\title{
Measuring Individuals' Misogynistic Attitudes: Development and Validation of the Misogyny Scale
}

\section{Bettina Rottweiler ${ }^{1} \mid$ Paul Gill $^{1}$}

${ }^{1}$ Security and Crime Science Department, University College London, United Kingdom

\section{Correspondence}

Bettina Rottweiler, Security and Crime Science Department, University College London, 35 Tavistock Square, London WC1H 9EZ, United Kingdom.

Email: bettina.rottweiler.16@ucl.ac.uk

\section{Funding information}

This study received funding from The European Research Council (ERC) under the European Union's Horizon 2020 research and innovation programme (Grant 758834). See https://www.grievance-erc.com.

This manuscript has not been peer reviewed. Contents may change prior to the publication. Version: 27/07/2021

Word Count: 9919 


\begin{abstract}
Across three studies based on a nationally representative survey $(n=1500)$, we developed and validated the misogyny scale. Initial items were generated from an extensive literature search and subsequently derived from validated scales assessing internalised misogyny, hostile sexism, and hostility towards women. Construct and measurement validity were established across several studies. An exploratory factor analysis (Study 1, $n=750$ ) established the factor structure of the 10-item misogyny scale. In study $2(n=750)$, the 10 -item structure was replicated via confirmatory factor analysis. The misogyny scale displayed good convergent (i.e., significant and strong relationship with male sexual entitlement, masculinity related violent beliefs and willingness to use violence) and discriminant validity (i.e., no relationship with analytical thinking). In study $3(n=750)$, we established measurement invariance across gender and age groups. This allows researchers to deploy the scale among male and female individuals, across different age groups as well as to assess latent mean differences. Significant latent mean differences for all three latent factors emerged between male and female participants, demonstrating that men had significantly stronger misogynistic attitudes than women $\left(\right.$ MDiff $_{1}=-.482 * * * ;$ MDiff $_{2}=-.324 * * * ;$ MDiff $\left._{3}=-.197 * * *\right)$. The latent mean differences ranged from small (Cohen's $d_{2}=.27$; Cohen's $d_{3}=.19$ ) to medium effect sizes (Cohen's $d_{l}=.38$ ). The strongest latent mean differences between age groups were found for the factor 'manipulative and exploitative nature of women'. Older age groups reported significantly stronger attitudes relating to this factor than younger participants. The misogyny scale will allow researchers to explore the psychological antecedents and consequences of misogyny among population samples and the subsequent findings may have important practical implications for prevention and intervention programs on violent (extremist) propensity development.
\end{abstract}

Keywords: misogyny, scale development, violent extremism, incels, domestic violence, gender-based violence 


\section{MEASURING INDIVIDUALS’'MISOGYNISTIC ATTITUDES}

\section{Introduction}

Public discourse on misogyny and its consequences is growing. Broad-based social movements (e.g., Me Too), violence prevention awareness programs, and highly publicised instances of harassment and violence against women consistently brought discussions of misogyny and related constructs (e.g., toxic masculinity) to the fore. In the United Kingdom, there are proposals to make misogyny a hate crime under the Domestic Abuse Bill currently under consideration. At the same time, different research designs demonstrate and argue the link between misogyny and domestic/family violence (Blake, O’Dean, Lian, \& Denson, 2021), sexual violence (Munsch \& Willer, 2012; Leone \& Parrott, 2019), harassment (Marwick \& Caplan, 2018), coercive control (Dragiewicz et al., 2018), the celebration of violence (Scaptura, 2019), and violent fantasies (Scaptura \& Boyle, 2020).

Increasingly, studies on violent extremism also highlight the role of misogyny (Díaz \& Valji, 2019; Hoffman Ware, \& Shapiro, 2020). Misogynistic worldviews form a core part of the extreme right's recruitment (Bjork-James, 2020; Center on Extremism, 2019) and misogyny has been a fundamental motive within recent far right terrorist attacks (Wilson, 2020), adding to the argument that misogyny may constitute a precursor for different forms of mass murder, including school shootings (Freeman, 2017; Neiwert, 2017; Wilson, 2018; Lyle \& Esmail, 2019; Muschert, 2007; Tyberg, 2016). Most evidently, misogyny is central to the 'involuntary celibate' movement. The violent fringe of this online subculture holds extreme misogynistic attitudes and advocates for violence against women (Ging, 2017; Maxwell, Robinson, Williams, \& Keaton, 2020). Since 2014, movement advocates, colloquially known as 'incels', conducted several acts of mass murders in the United States and Canada. These attacks were explicitly motivated by hatred towards women. Perpetrators expressed they sought vengeance for being unable to find a romantic partner and for being rejected by women (Bratich \& Banet-Weiser, 2019; Baele, Brace, \& Coan, 2019). 
Despite the increased public attention and scholarly research, the definitional boundaries of misogyny remain quite loose. Given this, it motivates a finer-grained measurement of misogyny, as well as an exploration of misogyny's psychological antecedents and consequences. Surprisingly, no validated psychometric tools that measure misogyny amongst males and females exist. ${ }^{1}$ This renders it vital to develop a tool that adequately measures the construct of misogyny. Hence this paper sought to develop a psychometric scale assessing the construct of misogyny. We do so across three studies which we now outline in turn.

\section{Study 1}

Study 1 attempted to gain a conceptual and theoretical understanding of misogyny. Psychometrically sound measures are fundamental to quantitative research. These tools have to be valid and reliable in order to generate robust findings. Yet, proper scale development techniques and reporting procedures are often absent or fragmented (Carpenter, 2018). Resultingly, methodological inconsistencies mean that standards of scale development vary (Davidson, Shaw, \& Ellis, 2020). We therefore draw from Carpenter's (2018) ten steps for scale development and introduce the misogyny scale: (1) Research the intended meaning and breadth of the theoretical concept (2) Determine sampling procedure (3) Examine data quality (4) Verify the factorability of the data (5) Conduct common factor analysis (6) Select factor extraction method (7) Determine number of factors (8) Rotate factors (9) Evaluate items based on a priori criteria (10) Present results.

\section{Step 1: Research the intended meaning and breadth of the theoretical concept}

Theoretical and conceptual research for scale development. We began the scale development process by trying to understand the meaning and breadth of the theoretical

\footnotetext{
${ }^{1}$ For an internalised misogyny scale for homosexual women see Piggott, 2004)
} 


\section{MEASURING INDIVIDUALS’'MISOGYNISTIC ATTITUDES}

concept and subsequently, to be able to identify potential dimensions of the construct and related items. If the scale dimensions and items adequately capture the intended representation of the abstract construct, meaningful measurement can be achieved (Carpenter, 2010; Chaffe, 1991). As such, it is important to ensure content validity of the construct before conducting the methodological applications and statistical analyses by taking several steps, such as trying to understand the extent of the construct and its dimension. Further steps include careful conceptualisation, such as finding suitable conceptual definitions, selecting appropriate conceptual labels for the overall constructs and its dimensions, as well as generating and refining items of the proposed scale. We conducted all of these steps as they have proven critical in the dimension identification and item generation process (DeVellis, 2012).

The literature review intended to provide an overview of the concept of 'misogyny'. We decided to broaden our literature search to further include related concepts to get a more holistic view of the construct and thus, to achieve a greater theoretical and conceptual understanding. The labelling of the construct and potential subscales affect future interpretations of the concept (Carpenter, 2018). We defined misogyny as the hatred or devaluation of, hostility to, or prejudice against women. However, our conceptualisation of misogyny does not include subtle sexism or gender bias in favour of men. Yet, we chose to also search for theoretically and conceptually related concepts, such as hostile sexism and more general hostility towards women. We conducted a literature search via Google Scholar on search items, such as "misogyny", "hostile sexism" and "hostility and/ or hatred towards women".

Scale dimension and item generation. The literature review process further intended to bring together existing questionnaires that measure misogyny, hostile sexism, or hostility towards women and consequently, to examine the different dimensions of the constructs and to identify potential subscales. While searching the literature for existing scales measuring the 
construct of misogyny, we were able to identify only one existing scale that was explicitly measuring misogyny. However, the focus of this scale was different to ours as it was specifically developed to assess homosexual women's internalised misogyny (Piggott, 2004). However, we further identified validated scales measuring hostile sexism, such as the subscale 'hostile sexism' of the Ambivalent Sexism Inventory (Glick \& Fiske, 1996), the Hostility Towards Women Scale (Check, Malamuth, Elias, \& Barton, 1985), as well as the Modern Sexism Scale (Swim, Aiken, Hall \& Hunter, 1995). We excluded the subscale 'benevolent sexism' of the Ambivalent Sexism Inventory (Glick \& Fiske, 1996), as we found that only the hostile sexism subscale aligned with our theoretical conceptualisation of misogyny. As such, we identified and developed the items based on the literature on misogyny specifically and sexism more generally. We identified several dimensions pertaining to the construct of misogyny and hostility towards women, yet the most common ones appeared to be related to the distrust of women, the devaluation of women and the manipulative and exploitative nature of women.

Generating and refining items. Several steps informed the compilation of items for our proposed scale. To set up our initial pool of items, we began by listing the existing tools of misogyny and hostile sexism published up until 2020. After compiling 44 items from 4 existing instruments that measure misogyny or hostile sexism, each item was reviewed individually. In the next step, we narrowed these measures down. More specifically, we either kept items without changing them, modified (e.g., due to slightly diverging conceptualisation), or removed (e.g., due to repetition/ redundancy or because they seemed unsuitable to capture our conceptual definition) individual items. We added five further items, pertaining to the manipulative and exploitative nature of women, as these attributes play a fundamental part in our conceptualisation of misogyny, but which had not been adequately assessed in previous measures. 
Feedback for scale item refinement. Before the main data collection, we conducted a pilot test $(n=40)$ via Prolific in June 2020. Respondents were not sampled based on any preset requirements. The pilot test was run to reduce response burden and to assess the possibility of measurement error, which can arise due to complex phrasing or language, lack of clarity in questions or response categories as well as leading or biased questions (Ruel, Wagner, \& Gillespie, 2016). We specifically asked participants whether the wording or meaning of any of the items was unclear or needed refinement and whether they had any other comments relating to response burden. None of the participants indicated lack of clarity of the survey items nor did they indicate a sign of response burden. After reviewing the individual items, the pilot test and peer feedback discussions, 19 of the 49 items remained. These 19 items were generated to assess the latent construct of misogyny and to create a scale for research purposes. Following several scale content development stages, we started our main data collection process.

\section{Method EFA}

Data collection procedure. We conducted a large scale general population survey in order to proceed with our scale development process. The primary purpose of this survey was to collect individual-level data on risk and protective factors for violent extremism. Yet, the secondary purpose was to collect data on the 19 items pertaining to the construct of misogyny and subsequently, to conduct the scale development and validation tests. Participants were recruited via Prolific. After completing the consent form, participants were asked to fill out the questionnaire. Unless stated otherwise, throughout all studies, all items were measured on a 7point scale ranging from 1 (strongly disagree) to 7 (strongly agree). After completing the questionnaire, the respondents were thanked and debriefed.

Participants. The main data collection took place in July 2020. Participants were part of a UK nationally representative sample (by age, gender, and ethnicity) $n=1500$. We split the whole sample in half in order to conduct an EFA on one half of the sample $(n=750)$ and to 
run the CFA on the other half of the sample $(n=750)$. In the EFA sample $51.2 \%(n=384)$ identified as female and $48.8 \%(n=366)$ identified as male $\left(M_{\mathrm{age}}=45.02 ; S D_{\mathrm{age}}=16.46\right)$. The majority of participants $(n=644 ; 85.5 \%)$ indicated 'White' as their ethnicity. This was followed by $7.7 \%(n=58)$ who stated 'Asian', $2.9 \%(n=22)$ who identified as 'Black' and $2 \%(n=22)$ as 'Mixed', as well as $1.5 \%(n=11)$ of all respondents answered 'Other'.

\section{Step 2: Determine sampling procedure}

The sample of $n=750$ exceeds previously recommended guidelines of a minimum of 300 participants (Worthington \& Whittaker, 2006). However, some call for abandoning the sample size logic and instead rely on item ratios as a way to determine sufficient sample sizes (Osborne, 2014). Costello and Osborne (2005) suggest at a 1:20 ratio of respondents to items as their findings found that these sample sizes produced the most robust and correct solutions. Our sample size translated into a 1:39 ratio, which allows us to achieve robust and generalisable results.

\section{Step 3: Examine Data Quality}

After data collection ended, we manually reviewed the dataset to ensure data quality and to examine any missing data. We examined whether participants had missed attention checks and we also reviewed the completion time for each respondent. We excluded participants from our data analysis if they missed more than one attention check and when they completed the survey more than two standard deviations quicker than the average survey completion time. We also assessed the 'Bot Detection' review. None of the 'participants' were flagged as potential bots. There was no missing data and responses on the misogyny items.

An exploratory factor analysis was conducted for evaluating the factor structure of the 19 items that comprised the preliminary misogyny scale. We conducted the EFA in the software programme R. We used the R package 'psych' to run the EFA analyses (Revelle, 2020). Further reliability analyses were conducted with the R package 'multilevel' (Bliese, 
2016). We decided to apply PAF rather than the maximum likelihood method as the former constitutes a more robust method and is recommended when the normality assumption is violated (Costello \& Osborne, 2005).

\section{Results EFA}

Step 4: Verify the Factorability of the Data. The first step was to verify the factorability of the data. Bartlett's test of sphericity is expected to be significant at $p<.05$, and the KaiserMeyer-Olkin (KMO) measure of sampling adequacy with a value of $\geq .60$ is recommended before proceeding with the exploratory factor analysis (Tabachnick \& Fidell, 2007). Bartlett's chi square test, $\chi^{2}(19)=503.91, p<.001$, and $\mathrm{KMO}=.95$ were inspected and demonstrated very good common variance as well as multivariate normality of the set of distributions, thereby verifying the factorability of the misogyny scale. Second, we inspected the correlation matrix. Carpenter (2018) suggests that inter-item correlations should be $\geq .30$. Items that do not correlate as such should be considered for deletion, if it makes theoretical sense to do so. All items correlated $\geq .30$.

Steps 5-7: Conduct Factor Analysis, Select Factor Extraction Method and Determine Number of Factors. Next, we conducted an EFA using the principal axis factoring (PAF) method and we ran a parallel analysis to establish how many factors to retain. Parallel analysis is one of the most accurate factor retention methods (Hayton, Allen, \& Scarpello, 2004; Kline, 2013). Parallel analysis compares eigenvalues of the EFA sample against a randomly ordered data set. Factors are retained if the sample's eigenvalues are larger than the ones pertaining to the random dataset (Carpenter, 2018). Based on the parallel analysis scree plot (Supplementary Materials A), a 5-factor solution was initially extracted.

\section{Step 8: Rotate Factors}




\section{MEASURING INDIVIDUALS’'MISOGYNISTIC ATTITUDES}

Next, we chose an oblique rotation technique, Promax, based on the assumption that the factors should be related to one another. Promax has been argued to be more robust than the Direct Oblimin rotation method, and thus is recommended (Thompson, 2004).

Step 9: Evaluate Items based on a Priori Criteria. We based scale item selection on several a priori criteria to decide which items to retain or delete. This was necessary in order to ensure consistency across the item selection process. We followed recommended guidelines (e.g., Kline, 2013; Tabachnick \& Fidell, 2007; Worthington \& Whittaker, 2006). First, items had to display a minimum factor item loading in order to be retained. We set the minimum loading at $>.50$, although Carpenter (2018) suggests loadings above .32 are acceptable. Further, items which cross-loaded on another factor above $>.32$ were excluded. The next inclusion criteria referred to a minimum of three items per factor. Factors with less than three items would be discarded. Additionally, we assessed items based on their theoretical convergence. More specifically, we examined whether individual items, loading onto the same factor, were found to demonstrate a clear conceptual grouping. Lastly, we retained or omitted items based on the principle of parsimony, which aimed to minimise the redundancy of wording or meaning across items. Non-parsimonious items were dropped (DeVellis, 2012).

The findings showed that two items showed loadings $<.50$ and were therefore removed. A further two items were omitted as they yielded cross-loadings $>.32$. One factor consisted of only two items and had to be excluded, as a minimum of three items per factor is required. Three items loaded onto the same factor, yet there was no clear conceptual grouping ('Women always feel offended'; 'I believe that most women do not tell the truth'; 'The intellectual leadership should be in the hands of men'). The latter of those items also showed a weak loading. These three items indicated poor theoretical convergence and therefore, they were also dropped. All non-excluded items and corresponding factors were found to be parsimonious. 
After deleting the above-mentioned items, we had 10 items left (see Table 1 for the misogyny scale after EFA).

Step 10: Present Results. Finally, we re-ran the EFA on the remaining 10 items using principal axis factoring analysis with Promax rotation. The results indicated a three-factor solution. Parallel analysis indicated that these three factors exceeded chance values and were above the simulated data (see Supplementary Materials B). There were no cross-loadings (> $.32)$ or weak loadings $(<.50)$ remaining. As a result, 3 factors and 10 items remained, factor 1 was comprised of four items, while factor 2 and factor 3 consisted of three items each (see Table 1 for the finalised scale). The sums of squared loadings are the factors' variances after extraction. Sums of squared loadings of $2.90,2.37$, and 1.53 emerged, representing $29 \%$, $23.7 \%$ and $15.3 \%$ of the variance, respectively, and explaining $68 \%$ of the total variance.

Inter-item reliability indices examine scale homogeneity and assess the level of consistency between multiple items measuring the same underlying construct. For instance, corrected item-total correlations are widely accepted item indices to assess item-score reliability (Zijlmans, van der Ark, Tijmstra, \& Sijtsma, 2018). A value of $\geq .30$ per item for the item-total correlation is considered to be sufficient, but researchers should aim for $.30-.70$ to achieve a greater degree of homogeneity (de Vaus, 2004). Our corrected item-total correlations ranged between $.57-.80$, indicating good scale homogeneity. We further assessed the communalities of items. Communalities $\left(h^{2}\right)$ are the sum of squared factor loadings for the variables. A communality indicates the proportion of each item's variance, which can be explained by the factors (e.g., the underlying latent construct). Communalities are considered satisfactory if they range between $.40-.70$ (Ibid). All item communalities of the misogyny ranged between $.44-.82$ (Table 1$)$.

Inter-item correlations were also examined as they present an essential element in conducting scale validity tests. Inspecting the inter-item matrix is a fundamental part of 


\section{MEASURING INDIVIDUALS’ MISOGYNISTIC ATTITUDES}

examining item redundancy. Cut-off scores are correlations below .20 and over .80, yet ideally the values should range between $.20-.50$ (Cohen \& Swerdlik, 2005). Our inter-item correlations varied between .32 -.76 (Supplementary Materials C). The misogyny scale yielded an average inter-item correlation of .55 , which is satisfactory. 
Table 1. Misogyny Scale final item selection and factor loadings obtained with exploratory factor analysis (EFA) in Study $1(n=750)$.

\begin{tabular}{|c|c|c|c|c|c|c|c|c|c|}
\hline \multirow[t]{2}{*}{ No. } & \multirow[t]{2}{*}{ Dimension } & \multirow[t]{2}{*}{ Item } & \multicolumn{3}{|c|}{ Factors } & \multirow[t]{2}{*}{ M (SD) } & \multirow[t]{2}{*}{ Skewness } & \multirow{2}{*}{$\begin{array}{l}\text { Corrected } \\
\text { item-total } \\
\text { correlation }\end{array}$} & \multirow[t]{2}{*}{$h^{2}$} \\
\hline & & & 1 & 2 & 3 & & & & \\
\hline 1 & $\begin{array}{l}\text { Manipulative and exploitative } \\
\text { nature of women }\end{array}$ & $\begin{array}{l}\text { Women seek to gain power } \\
\text { by getting control over men }\end{array}$ & .58 & & & $2.92(1.64)$ & .46 & .75 & .63 \\
\hline 2 & $\begin{array}{l}\text { Manipulative and exploitative } \\
\text { nature of women }\end{array}$ & $\begin{array}{l}\text { Women use their sexuality to } \\
\text { manipulate men }\end{array}$ & .92 & & & $3.70(1.75)$ & -.10 & .69 & .68 \\
\hline 3 & $\begin{array}{l}\text { Manipulative and exploitative } \\
\text { nature of women }\end{array}$ & $\begin{array}{l}\text { Women exploit men for their } \\
\text { own agendas }\end{array}$ & .88 & & & $2.75(1.64)$ & .58 & .81 & .80 \\
\hline 4 & $\begin{array}{l}\text { Manipulative and exploitative } \\
\text { nature of women }\end{array}$ & $\begin{array}{l}\text { If things don't go their way, } \\
\text { women will play the victim }\end{array}$ & .82 & & & $2.85(1.72)$ & .56 & .80 & .78 \\
\hline 5 & Distrust of women & $\begin{array}{l}\text { It is generally safer not to } \\
\text { trust women too much }\end{array}$ & & .83 & & $2.15(1.40)$ & 1.27 & .74 & .70 \\
\hline 6 & Distrust of women & $\begin{array}{l}\text { When it comes down to it a } \\
\text { lot of women are deceitful }\end{array}$ & & .94 & & $2.37(1.52)$ & 1.00 & .79 & .82 \\
\hline 7 & Distrust of women & $\begin{array}{l}\text { I think that most women } \\
\text { would lie just to get ahead }\end{array}$ & & .61 & & $2.46(1.54)$ & .95 & .81 & .72 \\
\hline 8 & Devaluation of women & $\begin{array}{l}\text { I think I get a raw deal from } \\
\text { women in my life }\end{array}$ & & & .60 & $2.06(1.33)$ & 1.27 & .62 & .52 \\
\hline 9 & Devaluation of women & $\begin{array}{l}\text { Sometimes women bother me } \\
\text { by just being around }\end{array}$ & & & .96 & $1.71(1.19)$ & 2.01 & .55 & .67 \\
\hline 10 & Devaluation of women & $\begin{array}{l}\text { I feel uncomfortable when a } \\
\text { woman dominates the } \\
\text { conversation }\end{array}$ & & & .54 & $1.68(1.08)$ & 1.79 & .57 & .44 \\
\hline
\end{tabular}

Note. Further displayed are the communalities $\left(h^{2}\right)$, corrected item-total correlations and additional descriptive statistics for all scale items 


\section{MEASURING INDIVIDUALS’'MISOGYNISTIC ATTITUDES}

The misogyny scale is a 3 -factor scale, whereby factor 1 contains four items and factor 2 as well as factor 3 each are composed of three items, reflecting underlying aspects of a misogynistic belief system $\left(M_{\text {Scale }}=2.46, S D=1.15\right)$. Each factor refers to a different, yet related aspect of the overall latent construct. The subscale naming logic aimed to identify an overarching 'concept' linking the individual items of each factor. We also compared our factor naming with the subscale labels of the hostile sexism and the internalised misogyny instruments (Glick \& Fiske, 1995; Piggott, 2004). Factor 1 'Manipulative and exploitative nature of women' included items that addressed individuals' attitudes about the manipulative and exploitative nature of women. Factor 2 'Distrust towards women' reflected a general distrust towards women. Lastly, Factor 3 'Devaluation of women' focused on items which referred to a general devaluation and derogation of women. All factors showed a strong positive correlation with one another. The 10-item misogyny scale displayed good factor loadings, satisfactory inter-item reliabilities (i.e., Communalities $h^{2}$ and total-item correlations) as well as a very good internal consistency (i.e., McDonald's $\omega$ ) for each subscale and thus, provides a psychometric instrument that represents misogynistic beliefs among a general population sample (see Table 2).

Table 2. Cronbach's alphas, means, SDs, and correlations between the three dimensions of the misogyny scale.

\begin{tabular}{llllll}
\hline Subscale & McDonald's & M (SD) & Factor & & $\mathbf{2}$ \\
& $\mathbf{\omega}$ & & $\mathbf{1}$ & $\mathbf{2}$ & $\mathbf{3}$ \\
\hline $\begin{array}{l}\text { 1. Manipulative and } \\
\text { exploitative nature of women }\end{array}$ & .91 & $3.05(1.49)$ & - & & \\
2. Distrust of women & .89 & $2.32(1.35)$ & $.75^{* * *}$ & - & \\
3. Devaluation of women & .80 & $1.82(.99)$ & $.57 * * *$ & $.66^{* * *}$ & - \\
\hline
\end{tabular}

Note: $* * * p<.001$. Correlation coefficient $r$ is reported. 


\section{Study 2}

In Study 2, we aimed to replicate the 3-dimentional factor structure of the misogyny scale via confirmatory factor analysis (CFA) and we further assessed the convergent and discriminant validity of the scale to confirm the structural and external aspects of construct validity. More specifically, we analysed the relationship between the misogyny scale and other constructs, which have been shown in past research to correlate with misogynistic and hostile sexist beliefs or where no significant relationship has been found and/or there is no theoretical reason to hypothesise such a relationship. The internal consistency (i.e., composite reliability) of the scale was also examined along with the average variance extracted (AVE).

\section{Method CFA}

Participants. As mentioned above, participants were part of a UK nationally representative sample (by age, gender, and ethnicity) $n=1500$ conducted in July 2020. We ran the CFA on the other half of the total sample $(n=750)$. In the CFA sample $51.3 \%(n=385)$ identified as female and $48.7 \%(n=365)$ identified as male $\left(M_{\text {age }}=44.82 ; S D_{\text {age }}=15.36\right)$. Out of all participants, $84 \%(n=630)$ stated 'White' as their ethnicity, 7.6\% $(n=57)$ answered 'Asian', 4.4\% $(n=33)$ identified as 'Black', 2.1\% $(n=16)$ as 'Mixed', as well as $1.9 \%(n=$ 14) answered 'Other'. The ratio of respondents to items was again 1:39, which exceeds the 1020 participants per item rule when conducting an CFA and thus, should ensure robust results (Schumacker \& Lomax, 2015).

Procedure. To validate our newly developed theoretical three-dimensional construct of misogyny, we applied a CFA. We ran the CFA on the second half $(n=750)$ of the total sample $\left(n_{\text {Total }}=1500\right)$ in order to confirm the structure of the proposed scale, which we obtained from the EFA analysis (Study 1) (Worthington \& Whittaker, 2006). We ran the models in the software program R using the packages 'Lavaan' (Rosseel, 2020) and 'SemTools' (Jorgensen, 2020). We evaluated multiple fit indices (i.e., $\chi^{2} / d f$, CFI, TLI, RMSEA, SRMR) to accept or 


\section{MEASURING INDIVIDUALS’ MISOGYNISTIC ATTITUDES}

reject our proposed and alternative models. Model fit was accepted if: the $\chi^{2} / d f$ ratio was fewer than three (Byrne, 2001), Comparative Fit Index (CFI) $\geq .90$, Tucker Lewis index (TLI) $\geq .90$, Root Mean Square Error of Approximation (RMSEA) $\leq .08$, Standardized Root Mean Square Residual $(\mathrm{SRMR}) \leq .08$ (Hu \& Bentler, 1999). We applied a robust estimator as the data displayed a skewed distribution, violating the normality assumption. As such, we conducted a maximum likelihood estimation with robust standard errors and a Satorra-Bentler scaled test statistic (Rosseel, 2020). Where available, we will report the robust fit indices.

\section{Results CFA}

The 3-factor model showed very good fit: $\chi^{2}(32)=94.55, p<.001, \chi^{2} / d f$ ratio $=2.95$; CFIRobust $=.982$, TLIRobust $=.975$, RMSEARobust $=.051 ;$ SRMR $=.029$ and thus, model fit was accepted. Factor loadings $\left(\lambda_{1-9}\right)$ ranged from $.71-.92$, demonstrating strong factor loadings (see Figure 1).

Figure 1. Confirmatory factor analysis of the 3-factor Misogyny Scale (Study 2)

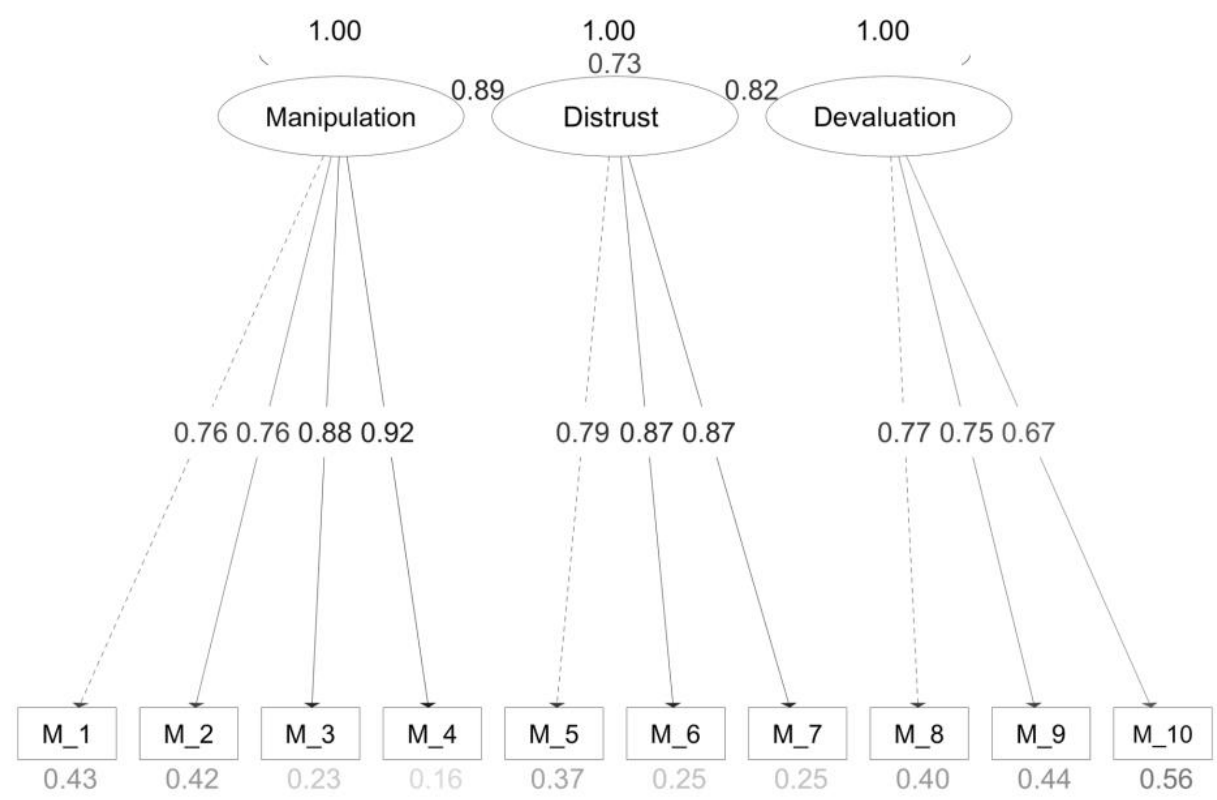

Note: Standardised coefficients are shown. All beta coefficients were statistically significant (all $p<.05$ ). 


\section{MEASURING INDIVIDUALS’'MISOGYNISTIC ATTITUDES}

Further, to ensure that the proposed model was the best fitting model, the 3-dimentional scale was compared to a unidimensional model, whereby all items loaded onto one factor. As expected, the 1-factor model displayed poor model fit: $\chi^{2}(35)=337.35, p<.001, \chi^{2} / d f$ ratio $=$ 9.64; CFI $_{\text {Robust }}=.913$, TLI $_{\text {Robust }}=.889, \mathrm{RMSEA}_{\text {Robust }}=.107 ;$ SRMR $=.055$. We further ran an ANOVA on both models to see whether the $\chi^{2}$ test was significant, which would indicate a statistically significant worse fit of the alternative model, and we further compared the alternative fit indices across models. Due to the non-normality of the data, we applied the Satorra-Bentler scaled chi-square difference test (Satorra \& Bentler, 2001). A significant $\chi^{2}$ test and a significant drop in fit indices: $\Delta \mathrm{CFI}=.01, \Delta \mathrm{TLI}=.01, \Delta \mathrm{RMSEA}=.015, \Delta \mathrm{SRMR}=.03$ would indicate that the alternative 1-factor model fit the data significantly worse and thus, would be rejected. Changes in $\chi^{2}$ parameters and fit indices are displayed as ' $\Delta$ '. The $\chi^{2}$ test was significant at $p<.001, \Delta \chi^{2}=242.80 ; \Delta d f=3$ and significant drops in fit indices emerged: $\Delta \mathrm{CFI}_{\text {Robust }}=.069, \Delta \mathrm{TLI}_{\text {Robust }}=.086, \Delta \mathrm{RMSEA}_{\text {Robust }}=.056, \Delta \mathrm{SMRM}=.026$. The 3-factor model yielded significant better fit rather than the alternative factor solution. We accepted the original 3-factor construct and the 1-factor model was rejected. Therefore, the misogyny scale is best conceptualised as a multidimensional model with three underlying factors, representing three underlying dimensions of misogynistic attitudes related to: (1) the manipulative and exploitative nature of women, (2) the distrust towards women, and (3) the devaluation of women.

The composite reliability (CR), McDonald's $\omega$, is a less biased estimate of reliability than Cronbach's alpha $(\alpha)$ as it takes into account the strength of association between items and constructs as well as item-specific measurement errors (Zinbarg, Revelle, Yovel, \& Li, 2005). An acceptable value for McDonald's $\omega$ is .7 and above. The internal consistencies for each factor of the misogyny scale ranged from good to excellent. AVE values $\geq .6$ are considered good, whereas values $\geq .5$ are acceptable (Hayes \& Coutts, 2020). The AVE was 
.60 or above for all factors. Next, correlations between all factors were moderate to strong (see Table 3). Correlations between manifest variables as well as latent correlations between latent factors can be found in the Supplementary Materials D.

Table 3. Correlations between the three dimensions of the misogyny scale as well as composite reliability, means and $S D$ s (Study 2).

\begin{tabular}{lllllll}
\hline Dimensions & $\begin{array}{l}\text { McDonald's } \\
\boldsymbol{\omega}\end{array}$ & M (SD) & AVE & F1 & F2 & F3 \\
\hline F1 & .90 & $3.14(1.48)$ & .69 & - & \\
F2 & .88 & $2.36(1.34)$ & .71 & $.79 * * *$ & - & \\
F3 & .77 & $1.86(1.05)$ & .60 & $.62 * * *$ & $.68^{* * *}$ & - \\
\hline
\end{tabular}

Note: $* * * p<.001$. AVE $=$ Average variance extracted. Correlation coefficient $r$ is reported.

Convergent and discriminant validity of the misogyny scale. Convergent and discriminant validity assessment are both fundamental aspects of construct validity (Piedmont, 2014). Convergent validity refers to how strongly a construct is related to measures of other latent constructs that are theorised to have causal relationships. Conversely, discriminant validity describes how well a measure performs in not being associated with theoretically dissimilar und unrelated concepts (Chin, Yao, 2014).

To test whether the misogyny scale has convergent validity, we explored constructs that have been shown to positively correlate with misogynistic and hostile sexist beliefs (e.g., sexual entitlement, Hill \& Fischer, 2001; tendency to seek revenge, Pina et al., 2017; hypermasculinity, Johnson, \& Knight, 2000; physical aggression, Forbes, Adams-Curtis, \& White, 2004). As anticipated, misogyny was positively correlated with sexual entitlement $(r=.45, p<.001$; $M$ SexualEntitlement $=1.70, S D=0.91)$ and tendency for revenge motivation $(r=.47, p<.001$; $M_{\text {Revenge }}=2.49, S D=1.33$ ). Additionally, misogyny was positively correlated to masculinity related violent beliefs $(r=.44, p<.001 ; M$ ViolentBeliefs $=1.76, S D=.91)$ as well as physical 
aggression $(r=.38, p<.001 ; M$ ViolentIntentions $=1.80, S D=1.03)$ Next, to examine discriminant validity, we explored the relationship with a construct where no relationship is expected. Our findings confirmed that there was no significant correlation between misogyny and a measure of analytical thinking $\left(r=-.06, p>.05, M_{\text {AnalyticalThinking }}=5.13, S D=.94\right)$.

\section{Study 3}

The third study was further designed to establish the generalisability aspect of construct validity, i.e., measurement validity. We conducted measurement invariance tests in order to ensure that the scale operates equivalently across comparison groups (Wang, Willett, \& Eccles, 2011), and subsequently estimated latent mean differences. Measurement invariance can establish whether group differences represent accurate mean differences rather than measurement bias (Dimitrov, 2010). More specifically, we examined whether there were significant gender and age group differences in regard to misogynistic attitudes. We also explored whether latent mean differences between younger and older individuals exist.

\section{Measurement invariance and latent mean comparisons}

Measurement invariance represents a fundamental step within the construct validation process. Self-report questionnaires consist of individual items, which are developed to assess an underlying latent construct. To be valid, (i.e., that the test is not biased against one group or another), measurement invariance has to be demonstrated (van de Schoot, Lugtig, \& Hox, 2012). Measurement invariance examines the psychometric equivalence of an instrument across groups or time and assesses whether a tool displays the same psychometric properties across heterogeneous groups (Chen, 2007). If a questionnaire measures an identical construct with the same structure and meaning across groups or time points, the assessment instrument is called measurement invariant (van de Schoot et al., 2012). Conversely, if a psychometric construct demonstrates measurement noninvariance, it suggests that the instrument has a different structure or meaning to different groups (e.g., male and female participants) or across 
different measurement points (e.g., pre-test and post-test), and thus the tools cannot be meaningfully tested or interpreted across groups or across time (Putnick \& Bornstein, 2016).

Measurement invariance analysis examines whether the factor loadings and intercepts/ thresholds, from which the latent factor scores are created, are equal across groups (Meredith, 1993). Therefore, it is required to establish measurement invariance prior to testing for group mean differences of latent constructs as latent means cannot be adequately assessed and compared when measures are noninvariant (Cheung \& Rensvold, 2002). This refers to a key issue of analyses comparing group means of latent constructs. Observed composite scores on which most group comparison analyses (e.g., T-tests, ANOVAs) are based, cannot simply be equated with the latent or true means of the underlying construct. Instead, the relationship between an observed mean and the latent factor mean is a probabilistic function, which includes two further important parameters - the indicator intercepts/ thresholds and the factor loadings - which link individual indicators to the latent construct (Steinmetz, 2010; Sass, 2011). Yet, it is common practice to compare means and other statistics of latent constructs across groups without establishing strong factorial invariance (i.e., establishing that factor loadings and intercepts/thresholds are equal across groups or measurement occasions). The violation of the measurement invariance assumption can lead to inaccurate inferences of group comparisons (Yuan \& Chan, 2016). For instance, when measurements are non-invariant across groups, the observed group mean difference may simply be due to differential meaning or understanding of the construct or particular items across groups (Sass, 2011).

\section{Method Measurement Invariance}

Participants. The measurement invariance tests as well as the latent mean comparisons are based on the same sample as study 2 .

Procedure. We ran all analyses within study 3 in the software program $\mathrm{R}$ using the packages 'Lavaan' (Rosseel, 2020) and 'SemTools' (Jorgensen, 2020). We tested for strong 


\section{MEASURING INDIVIDUALS’'MISOGYNISTIC ATTITUDES}

factorial invariance across gender and age groups. Measurement invariance is tested within the framework of multiple-group confirmatory factor analysis (MGCFA). The procedure in our analysis involved testing for configural, measurement, and structural invariance (e.g., equality of group means) (for an outline of the full procedure see Chen, Sousa, \& West, 2005; Putnick \& Bornstein, 2016; van de Schoot et al., 2012). The MGCFA process consists of conducting multiple hierarchically nested confirmatory factor analyses by incrementally increasing levels of group equality constraints (e.g., constraining factor loadings and thresholds across groups). Typically, model evaluation includes testing whether the differences between these models are statistically significant and/ or assessing the change in magnitudes of fit indices to see if more restricted models perform less well, suggesting that instruments are noninvariant (Gregorich, 2006). More specifically, to decide whether invariance can be confirmed or not, the majority of analyses either use the chi-square difference test $\left(\Delta \chi^{2}\right)$ and/ or examine the change in magnitudes of accepted fit indices (i.e., $\triangle \mathrm{AFI}$ ) between two nested models.

A significant limitation of the $\chi^{2}$ test is its inherent sensitivity to reject the null hypothesis when analyses include large samples as well as complex models. Chi-square difference tests have been found to reject adequate models if the sample size is large but conversely, fail to reject poor models if the sample is rather small (van de Schoot et al., 2016). Due to our large sample size and the relatively complex model structure of the misogyny scale, a multidimensional construct with three latent underlying factors, we decided to employ alternative fit statistics, such as CFI, TLI, RMSEA and SRMR, which adjust for sample size and model complexity. This procedure is increasingly employed within MGCFA analyses and researcher recommend applying this approach if models are based on large samples and contain a complex structure (e.g., Chen, 2007; Cheung \& Rensvold, 2002).

Hence, we compared the changes in model fit statistics for the invariance models to the previous, less restrictive model and we further evaluated the overall model fit for each 
individual model. We compared the $\Delta \mathrm{CFI}, \Delta \mathrm{TLI}, \triangle \mathrm{RMSEA}, \triangle \mathrm{SRMR}$ rather than $\chi^{2}$ difference test and based our cut-off criteria for model evaluation on recommendations made by Chen (2007). As such, acceptable model fit for more restrictive invariant models are: $\Delta$ CFI $<0.01$, $\Delta \mathrm{TLI}<0.01, \Delta \mathrm{RMSEA}<0.015$, and $\Delta \mathrm{SRMR}<0.03$ for metric invariance (i.e., equal factors loadings) and $\Delta \mathrm{CFI}<0.01, \Delta \mathrm{TLI}<0.01, \Delta \mathrm{RMSEA}<0.015$, and $\triangle \mathrm{SRMR}<0.01$ for scalar invariance (i.e., equal items intercepts). Yet, the $\Delta \chi^{2}(\Delta d f)$ can be found in the Supplementary Materials F. We applied a Satorra-Bentler scaled (mean-adjusted) chi-square difference test $\left(\mathrm{SB} \chi^{2}\right)$ due violations of the normality assumption of the data. The $\mathrm{SB} \chi^{2}$ is the normal $\chi^{2}$ divided by a scaling correction to improve the approximate chi-square under non-normality (Satorra \& Bentler, 2001). Due to the non-normal distribution of the data, we ran all MGCFA models with a robust estimator, MLM, which applies maximum likelihood parameter estimates with standard errors and a mean-adjusted chi-square test statistic that are robust to non-normality (Lavaan, 2021).

\section{Results}

Measurement Invariance - Gender. First, we ran separate CFAs for both male and female groups to assess the factor loadings and fit indices before we proceeded with the multigroup confirmatory analyses. Findings indicated strong factor loadings and good fit indices for each group, suggesting adequate factorial validity and thus, allowed us to pursue the measurement invariance tests (see Supplementary Materials E, for an overview of measurement invariance results see Supplementary Materials F). Next, we tested for configural invariance (CI), i.e., form invariance, which examines the invariance of the model configuration, which is another prerequisite before testing for measurement invariance. The CI analysis assesses the factor structure of latent constructs and a baseline model is estimated for each group. If the number and pattern of factors and indicator loadings are equal across groups, configural invariance is supported (Dimitrov, 2010; Vandenberg \& Lance, 2000). The fit 
indices for the CI model showed good model fit: $\chi^{2}(64)=142.36, p<0.001 ; \chi^{2} / d f$ ratio $=2.22$; $\mathrm{CFI}_{\text {Robust }}=.978$, TLI $_{\text {Robust }}=.969$, RMSEA $_{\text {Robust }}=.057 ;$ SRMR $=.032$, confirming configural invariance across genders. Configural invariance justified the evaluation of more restrictive invariance models.

The following step involved testing for metric invariance, (i.e., the equivalence of individual item loadings on the latent factors). Metric invariance is tested by constraining factor loadings to be equivalent across groups (van de Schoot et al., 2012). Findings of the metric invariance test showed that the model fit the data well: $\chi^{2}(71)=167.03, p<0.001 ; \chi^{2} / d f$ ratio $=2.35 ; \mathrm{CFI}_{\text {Robust }}=.974, \mathrm{TLI}_{\text {Robust }}=.967, \mathrm{RMSEA}_{\text {Robust }}=.060 ; \mathrm{SRMR}=.050$. The change of fit indices, i.e., $\Delta \mathrm{CFI}=-.004, \Delta \mathrm{TLI}=-.002, \Delta \mathrm{RMSEA}=-.003$ as well as $\Delta \mathrm{SMRM}=-.018$ between the configural and metric invariance model were all within the thresholds outlined above, supporting metric invariance across men and women. Next, tests for scalar invariance were conducted. Scalar invariance assesses the equivalence of item intercepts or indicator means across groups. This is tested by constraining item intercepts to be equivalent in the respective groups (Chen et al., 2005; Putnick \& Bornstein, 2016). Invariance testing comparing female and male individuals suggested good model fit across all indices at the scalar level: $\chi^{2}$ $(78)=207.12, p<0.001 ; \chi^{2} / d f$ ratio $=2.66 ; \mathrm{CFI}_{\text {Robust }}=.971, \mathrm{TLI}_{\text {Robust }}=.963, \mathrm{RMSEA}_{\text {Robust }}=$ $.063 ; \mathrm{SRMR}=.053$. Evaluation of scalar invariance showed acceptable changes in fit indices: $\Delta \mathrm{CFI}=-.003, \Delta \mathrm{TLI}=-.004, \Delta \mathrm{RMSEA}=-.003$ as well as $\Delta \mathrm{SMRM}=-.003$. Our findings confirmed strong factorial invariance of the misogyny scale, indicating that our scales measured comparable constructs among males and females.

Latent mean differences - Gender. Once we were able to confirm measurement invariance for the misogyny scale across men and women, we tested for structural invariance (i.e., the equality of latent factor means across gender groups). More specifically, we examined whether there were any latent mean differences on the three latent factors between female and 
male individuals. If the factor means in the reference group are fixed to zero, the estimated latent factor means in the other groups show the relative differences between the groups (Sass, 2011). The male group in our analyses was treated as the reference group while comparing the latent means to the female group. Therefore, we fixed the latent means of the male group to zero and therefore, the latent means of the three factors in the comparison group (i.e., females) show the mean differences between the two groups. Additionally, we report the effect size Cohen's $d$ to allow comparisons across analyses. The latent mean differences and Cohen's $d$ for all models are displayed in the Supplementary Materials G.

We tested for structural invariance by constraining the structural coefficients (i.e., latent means) to be equal across groups. We evaluated the $\chi^{2}$ difference test $\left(\Delta \chi^{2}\right)$ in order to determine whether significant group mean differences exists. The structural invariance analysis revealed a significant test: $\Delta \chi^{2}(3)=22.66, p<.001$, evaluating the two nested models, one having the latent means constrained to be equal, and the other one freely estimating those. Posthoc tests confirmed significant $\Delta \chi^{2}$ on all latent factors between males and females, which indicates that significant gender mean differences on all subscales: (1) manipulative and exploitative nature of women (2) distrust towards women and (3) devaluation of women, exist. Results showed that men report significantly stronger misogynistic attitudes than women for all three latent factors: MDiff $_{1}=-.482 * * *$ (manipulative and exploitative nature of women), MDiff $_{2}=-.324 * * *$ (distrust towards women), and MDiff $_{3}=-.197 * * *$ (devaluation of women). The Cohen's $d$ indices show that the values of effect size for the factor 'manipulative and exploitative nature of women' $\left(d_{l}=.38\right)$ is medium, whereas the factors 'distrust towards women' $\left(d_{2}=.27\right)$ as well as 'devaluation of women' $\left(d_{3}=.19\right)$ display small effect sizes.

Measurement Invariance - age groups. For the age group measurement invariance tests, we applied the same sequential constraint imposition approach, which we used for the gender measurement invariance tests. The tests followed a logical sequence of nested models 
ordered in an increasingly restrictive fashion. At each step, we evaluated the difference of multiple fit indices to decide whether invariance is accepted or rejected (see Dimitrov, 2010). To start with, we inspected separate CFAs for all three age groups: (1) individuals aged 18-29 (2) individuals aged 30-49 (3) individuals aged 50-82. The fit indices showed good model fit for each group (see Supplementary Materials $G$ for also non-significant differences). Configural invariance model across age groups demonstrated satisfactory fit indices, which supported invariance of the configural model. The metric invariance model with factor loadings being restricted to be equal, yielded very good model fit, which suggests that the model fits the data well: $\chi^{2}(110)=188.07, p<0.001 ; \chi^{2} / d f$ ratio $=1.71 ; \mathrm{CFI}_{\text {Robust }}=.979$, TLI $_{\text {Robust }}=.975$, RMSEARobust $=.053 ;$ SRMR $=.053$. Additionally, the change of fit indices between configural and metric invariance models showed that $\Delta \mathrm{CFI}=-.004, \Delta \mathrm{TLI}=-.002, \Delta \mathrm{RMSEA}=-.002$ as well as $\triangle \mathrm{SMRM}=-.020$ were all within the thresholds of 0.01 and 0.03 , respectively. These results confirm metric invariance across age groups. The scalar invariance model also presented good model fit: $\chi^{2}(124)=234.91, p<0.001 ; \chi^{2} / d f$ ratio $=1.89 ; \mathrm{CFI}_{\text {Robust }}=.975$, $\mathrm{TLI}_{\text {Robust }}=.972, \mathrm{RMSEA}_{\text {Robust }}=.057 ; \mathrm{SRMR}=.057$. The scalar invariance analysis further revealed that the indicators' intercepts were invariant across age groups, as the change between the scalar and metric invariance tests were all within the thresholds for scalar invariance testing: $\Delta \mathrm{CFI}=-.004, \Delta \mathrm{TLI}=-.003, \Delta \mathrm{RMSEA}=-.004$, and $\Delta \mathrm{SMRM}=-.004$.

Latent mean differences - age groups. Based on the establishment of measurement invariance across age groups, we further compared the latent mean differences across these age groups. We assessed the equality of factor means by comparing two nested models, one had the latent means constrained to be equal and the other model estimated those freely. Findings from the structural invariance test revealed significant differences between age groups. The constrained model had a significantly worse fit, indicated via a significant $\chi^{2}$ test between models: $\Delta \chi^{2}(6)=32.71, p<.001$ as well as a notable drop in fit indices. Several post hoc tests 
were run, each time comparing $\Delta \chi^{2}$ among another set of age groups, i.e., (1) group 1 and 2, (2) group 1 and 3, as well as (3) group 2 and 3. Several significant differences emerged between age groups. Results revealed that latent mean differences existed for the first (manipulative and exploitative nature of women) and third latent factor (devaluation of women) of the misogyny scale but not for the second later factor (distrust towards women).

Manipulative and exploitative nature of women. Overall, results showed that younger individuals hold weaker attitudes about the manipulative and exploitative nature of women. Specifically, age group 1 (individuals aged 18-29) reported significantly weaker attitudes referring to the manipulative and exploitative nature of women than age group 2 (individuals aged 30-49) $\left(\right.$ MDiff $\left._{1}=.187^{* * *}, d_{1}=.14\right)$. Age group 1 also reported weaker attitudes than group 3 (individuals aged $50-82)$ on this factor $\left(\operatorname{MDiff}_{2}=.333^{* * *}, d_{2}=.28\right)$. Further, the latent factor mean for group 3 was significantly larger than for group 2, which demonstrated that group 3 holds stronger misogynistic attitudes relating to the manipulative and exploitative nature of women $\left(\mathrm{MDiff}_{3}=.166 * * *, d_{3}=.13\right)$.

Devaluation of women. In regard to our third latent factor addressing the 'devaluation of women', on average, younger individuals reported stronger attitudes than older participants. Our results showed that the latent factor mean for age group 1 was significantly larger than the mean for age group $3\left(\right.$ MDiff $\left._{4}=-.159 * * *, d_{4}=.17\right)$, indicating that younger individuals hold stronger attitudes, which capture the devaluation of women. Additionally, we found that age group 2 scored significantly higher on this latent factor than age group 3 in our sample $\left(\right.$ MDiff $\left._{5}=-.159 * * *, d_{5}=.14\right)$. However, we did not find any significant latent mean differences between group 1 and 2 for this latent factor. Overall, we did not find any significant differences for the second latent factor 'distrust towards women'. 


\section{MEASURING INDIVIDUALS’'MISOGYNISTIC ATTITUDES}

\section{Discussion}

Recent incidents have demonstrated that misogynistic beliefs can lead to acts of violence. Manifestos of incel as well as far-right terrorist attackers have repeatedly shown that the perpetrators espoused extreme misogynistic attitudes (Maxwell et al., 2020; Wilson, 2020). Misogyny has further been characterised as a key motivating factor within extremist recruitment and ideologies (Center on Extremism, 2019). These incidents clearly demonstrate that misogyny represents an urgent topic which requires more research. Yet, the topic of misogyny is particularly under-researched, which became clear when searching for existing studies or psychometric scales assessing the concept. Across several studies, the present work has developed and validated a novel measure of misogynistic attitudes that is suitable for population samples. Overall, the misogyny scale displays robust psychometric properties. It has been shown to be reliable and valid in assessing misogynistic beliefs among the general population. In study 1 , using exploratory factor analysis, a 10-item scale with three latent factors was identified. The factors were labelled 'manipulative and exploitative nature of women', distrust towards women', and 'devaluation of women', each consisting of three items.

All item communalities showed satisfactory correlations and item-total correlations showed good scale homogeneity and inter-item reliability. The misogyny scale displayed very good internal consistency, indicated by high values of McDonald's $\omega$ across all factors. In Study 2, the 3-dimensional factor structure was replicated via confirmatory factor analysis, demonstrating very good model fit. All three factors showed high internal reliabilities. Further, the scale displayed good convergent (i.e., relationship with sexual entitlement, violent beliefs, physical aggression as well as revenge motivations) and discriminant (i.e., no relationship with analytical thinking) validity. Study 3 demonstrated the significance of establishing measurement invariance before comparing latent factor means. More specifically, measurement invariance testing allows researchers to identify those items that are problematic 
or noninvariant, which in turn may enhance the development of new or revised items or instruments. We established full factorial invariance of the misogyny scale across gender and age groups. Latent mean analyses highlighted the differences for different latent factors between men and women as well as between older and younger individuals.

While this paper offers a valuable contribution to studying the concept of misogyny, it is important to acknowledge several limitations. First, we did not assess test-retest reliability of the misogyny scale and therefore, we were not able to examine the stability of the misogyny scale over time. Further research should test for test-retest reliability and assess the intra-class coefficient (ICC) as well as conduct paired samples' t-tests to confirm the scale's repeatability. Relatedly, another shortcoming is the fact that our scale development is solely based on a crosssectional research design so far. Future research should collect longitudinal data to test for the predictive validity of the misogyny scale and to conduct the above-mentioned reliability tests.

Additionally, it would also be beneficial to assess the relationship of our newly developed misogyny scale and existing scales measuring closely related concepts, such as hostile sexism. Strong correlations would suggest convergent validity. Lastly, our misogyny scale will most likely be dependent on the cultural context where the scale is applied and as such, may not be applicable to non-WEIRD (Western, educated, industrialised, rich, and democratic) countries. The concepts of women's rights and the role of women within society more broadly and that of misogyny more specifically, vary heavily between countries and are progressive issues which constantly change and adapt. As such, no universal measure of misogyny should be expected. Studies operationalising the scale should think carefully whether the underlying latent construct is applicable to the respective study context. Further, all studies using the scale should run a CFA to confirm the factor structure and should conduct measurement invariance test to see whether the scale possesses measurement validity in that specific sample. 


\section{MEASURING INDIVIDUALS’ MISOGYNISTIC ATTITUDES}

\section{Conclusion}

Taken together, the current paper makes important first steps in establishing a conceptualisation of misogyny, which may be used in future survey studies and may encourage further research in this area. Given the prevalence of extreme misogynistic beliefs among incel as well as far right extremists and the fundamental role these attitudes have shown to play in motivating acts of violence, P/CVE programs and violent risk assessment approaches should more strongly incorporate those concepts into their work.

\section{References}

Baele, S. J., Brace, L., \& Coan, T. G. (2019). From "Incel" to "Saint": Analyzing the violent worldview behind the 2018 Toronto attack. Terrorism and Political Violence, 1-25.

Bjork-James, S. (2020). White sexual politics: the patriarchal family in white nationalism and the religious right. Transforming Anthropology, 28(1), 58-7.

Blake, K. R., O’Dean, S. M., Lian, J., \& Denson, T. F. (2021). Misogynistic tweets correlate with violence against women. Psychological science, 0956797620968529.

Bliese, P., \& Bliese, M. P. (2016). Package 'multilevel'. $R$ version, 2.

Bratich, J., \& Banet-Weiser, S. (2019). From pick-up artists to incels: con (fidence) games, networked misogyny, and the failure of neoliberalism. International Journal of Communication, 13, 25.

Byrne, B. M. (2001). Structural equation modeling with AMOS, EQS, and LISREL: Comparative approaches to testing for the factorial validity of a measuring instrument. International journal of testing, 1(1), 55-86. 


\section{MEASURING INDIVIDUALS’ MISOGYNISTIC ATTITUDES}

Carpenter, S. (2018). Ten steps in scale development and reporting: A guide for researchers. Communication Methods and Measures, 12(1), 25-44.

Casey, E. A., Masters, N. T., Beadnell, B., Hoppe, M. J., Morrison, D. M., \& Wells, E. A. (2017). Predicting sexual assault perpetration among heterosexually active young men. Violence against women, 23(1), 3-27.

Center on Extremism (2018) When women are the enemy: The intersection of misogyny and white supremacy. ADL Center on Extremism Report. New York.

Chaffee, S.H. (1991) Communication Concepts 1: Explication. Newbury Park, CA: Sage.

Check, J. V., Malamuth, N. M., Elias, B., \& Barton, S. (1985). On hostile ground. Psychology Today, 19(4), 56-61.

Chen, F. F. (2007). Sensitivity of goodness of fit indexes to lack of measurement invariance. Structural equation modeling: a multidisciplinary journal, 14(3), 464-504.

Chen, F. F., Sousa, K. H., \& West, S. G. (2005). Testing measurement invariance of secondorder factor models. Structural Equation Modeling, 12, 471-492.

Cheung, G. W., \& Rensvold, R. B. (2002). Evaluating goodness-of-fit indexes for testing measurement invariance. Structural equation modeling, 9(2), 233-255.

Chin CL., Yao G. (2014) Convergent Validity. In: Michalos A.C. (Eds.) Encyclopedia of Quality of Life and Well-Being Research. Springer, Dordrecht.

Cohen, R. J., \& Swerdlik, M. E. (2005). Psychological testing and assessment: An introduction to tests and measurement. Boston: McGraw-Hill. 
Costello, A. B., \& Osborne, J. W. (2005). Best practices in exploratory factor analysis: Four recommendations for getting the most from your analysis. Practical Assessment, Research \& Evaluation, 10(7), 1-9.

Davidson, B. I., Shaw, H., \& Ellis, D. A. (2020). Fuzzy constructs in assessment: The overlap between mental health and technology "use.". Open Science Framework.

De Vaus, D. (2004). Surveys in Social Research (5th ed.). London: Routledge.

DeVellis, R. F. (2012). Scale development. Theory and applications (3rd ed.). Thousand Oaks, CA: Sage.

Diaz, P. C., \& Valji, N. (2019). Symbiosis of Misogyny and Violent Extremism. Journal of International Affairs, 72(2), 37-56.

Dimitrov, D. M. (2010). Testing for factorial invariance in the context of construct validation. Measurement and Evaluation in Counseling and Development, 43(2), 121149.

Dragiewicz, M., Burgess, J., Matamoros-Fernández, A., Salter, M., Suzor, N. P., Woodlock, D., \& Harris, B. (2018). Technology facilitated coercive control: Domestic violence and the competing roles of digital media platforms. Feminist Media Studies, 18(4), 609625.

Forbes, G. B., Adams-Curtis, L. E., \& White, K. B. (2004). First-and second-generation measures of sexism, rape myths and related beliefs, and hostility toward women: Their interrelationships and association with college students' experiences with dating aggression and sexual coercion. Violence against women, 10(3), 236-261.

Ging, D. (2017). Alphas, Betas, and Incels: Theorizing the Masculinities of the Manosphere. Men and Masculinities. Advance online publications. 


\section{MEASURING INDIVIDUALS’ MISOGYNISTIC ATTITUDES}

Glick, P., \& Fiske, S. T. (1996). The ambivalent sexism inventory: Differentiating hostile and benevolent sexism. Journal of personality and social psychology, 70(3), 491.

Gregorich, S. E. (2006). Do self-report instruments allow meaningful comparisons across diverse population groups? Testing measurement invariance using the confirmatory factor analysis framework. Medical care, 44(11 Suppl 3), S78.

Hayton, J. C., Allen, D. G., \& Scarpello, V. (2004). Factor retention decisions in exploratory factor analysis: A tutorial on parallel analysis. Organizational research methods, 7(2), 191-205.

Hayes, A. F., \& Coutts, J. J. (2020). Use omega rather than Cronbach's alpha for estimating reliability. But.... Communication Methods and Measures, 14(1), 1-24.

Hill, M. S., \& Fischer, A. R. (2001). Does entitlement mediate the link between masculinity and rape-related variables? Journal of Counseling Psychology, 48(1), 39-50.

Hoffman, B., Ware, J., \& Shapiro, E. (2020). Assessing the threat of incel violence. Studies in Conflict \& Terrorism, 43(7), 565-587.

Hu, L. T., \& Bentler, P. M. (1999). Cutoff criteria for fit indexes in covariance structure analysis: Conventional criteria versus new alternatives. Structural equation modeling: a multidisciplinary journal, 6(1), 1-55.

Jason Wilson, "What Do Incels, Fascists, and Terrorists Have in Common? Violent Misogyny" Guardian, 4 May 2018.

Johnson, G. M., \& Knight, R. A. (2000). Developmental antecedents of sexual coercion in juvenile sexual offenders. Sexual Abuse: A Journal of Research and Treatment, 12(3), $165-178$. 
Jorgensen, T. D., Pornprasertmanit, S., Schoemann, A. M., \& Rosseel, Y. (2020). semTools: Useful tools for structural equation modeling.

Kline, R. B. (2013). Exploratory and confirmatory factor analysis. In Y. Petscher, C. Schatschneider, \& D. L. Compton (Eds.), Applied quantitative analysis education and the social sciences (pp. 171-207). New York, NY, USA: Routledge.

Leone, R. M., \& Parrott, D. J. (2019). Misogynistic peers, masculinity, and bystander intervention for sexual aggression: Is it really just "locker-room talk?". Aggressive behavior, 45(1), 42-51.

Lyle, P., \& Esmail, A. (2019). Mass Shooting and Misogyny: Broken Males are Pulling the Trigger.

Marwick, A. E., \& Caplan, R. (2018). Drinking male tears: Language, the manosphere, and networked harassment. Feminist Media Studies, 18(4), 543-559.

Munsch, C. L., \& Willer, R. (2012). The role of gender identity threat in perceptions of date rape and sexual coercion. Violence Against Women, 18(10), 1125-1146.

Maxwell, D., Robinson, S. R., Williams, J. R., \& Keaton, C. (2020). “A Short Story of a Lonely Guy": A Qualitative Thematic Analysis of Involuntary Celibacy Using Reddit. Sexuality \& Culture, 1-23.

Meredith, W. (1993). Measurement invariance, factor analysis and factorial invariance. Psychometrika, 58(4), 525-543.

Osborne, J. W. (2014). Best practices in exploratory factor analysis. Scotts Valley, CA: CreateSpace Independent Publishing. 
MEASURING INDIVIDUALS’'MISOGYNISTIC ATTITUDES

Piggot, M. (2004). Double jeopardy: Lesbians and the legacy of multiple stigmatized identities. Unpublished thesis, Psychology Strand at Swinburne University of Technology, Australia.

Pina, A., Holland, J., \& James, M. (2017). The malevolent side of revenge porn proclivity: Dark personality traits and sexist ideology. International Journal of Technoethics (IJT), 8(1), 30-43.

Piedmont R.L. (2014) Construct Validity. In: Michalos A.C. (eds) Encyclopedia of Quality of Life and Well-Being Research. Springer, Dordrecht

Putnick, D. L., \& Bornstein, M. H. (2016). Measurement invariance conventions and reporting: The state of the art and future directions for psychological research. Developmental review, 41, 71-90.

Revelle, W. (2018). psych: Procedures for psychological, psychometric, and personality research. $R$ package version, $1(10)$.

Rosseel, Y. (2012). Lavaan: An R package for structural equation modeling and more. Version 0.5-12 (BETA). Journal of statistical software, 48(2), 1-36.

Ruel, E., Wagner III, W. E., \& Gillespie, B. J. (2015). The practice of survey research: Theory and applications. Sage Publications.

Sass, D. A. (2011). Testing measurement invariance and comparing latent factor means within a confirmatory factor analysis framework. Journal of Psychoeducational Assessment, 29(4), 347-363.

Satorra, A., \& Bentler, P. M. (2001). A scaled difference chi-square test statistic for moment structure analysis. Psychometrika, 66(4), 507-514. 
MEASURING INDIVIDUALS’ MISOGYNISTIC ATTITUDES

Scaptura, M. N. (2019). Masculinity Threat, Misogyny, and the Celebration of Violence in White Men (Doctoral dissertation, Virginia Tech).

Scaptura, M. N., \& Boyle, K. M. (2020). Masculinity threat,“Incel” traits, and violent fantasies among heterosexual men in the United States. Feminist Criminology, 15(3), 278-298.

Smith, J. (2019). 'When I Saw Women Being Attacked... It Made Me Want to Stand Up and Fight': Reporting, Responding to, and Resisting Online Misogyny. In Online Othering (pp. 287-308). Palgrave Macmillan, Cham.

Steinmetz, H. (2011). Estimation and comparison of latent means across cultures. Crosscultural analysis: Methods and applications, 85-116.

Swim, J. K., Aikin, K. J., Hall, W. S., \& Hunter, B. A. (1995). Sexism and racism: Oldfashioned and modern prejudices. Journal of personality and social psychology, 68(2), 199.

Tabachnick, B. G., \& Fidell, L. S. (2007). Using multivariate statistics (5th ed.). Boston, MA: Allyn and Bacon.

Thompson, B. (2004). Exploratory and confirmatory analysis: Understanding concepts and applications. Washington, DC, USA: American Psychological Association.

Tyberg, S. A. (2016). Entitlement and Anguish: An Analysis of Masculinity and Misogyny in American School Shootings. Dickinson College Honors Theses. Paper 224.

Van de Schoot, R., Lugtig, P., \& Hox, J. (2012). A checklist for testing measurement invariance. European journal of developmental psychology, 9(4), 486-492.

Vandenberg, R. J., \& Lance, C. E. (2000). A review and synthesis of the measurement invariance literature: Suggestions, practices, and recommendations for organizational research. Organizational research methods, 3(1), 4-70. 


\section{MEASURING INDIVIDUALS’ MISOGYNISTIC ATTITUDES}

Wang, M. T., Willett, J. B., \& Eccles, J. S. (2011). The assessment of school engagement: Examining dimensionality and measurement invariance by gender and race/ethnicity. Journal of School Psychology, 49(4), 465-480.

Worthington, R. L., \& Whittaker, T. A. (2006). Scale development research. A content analysis for recommendations for best practices. The Counseling Psychologist, 34(6), 806-838.

Yuan, K. H., \& Chan, W. (2016). Measurement invariance via multigroup SEM: Issues and solutions with chi-square-difference tests. Psychological methods, 21(3), 405.

Zinbarg, R. E., Revelle, W., Yovel, I., \& Li, W. (2005). Cronbach's $\alpha$, Revelle's $\beta$, and McDonald's $\omega \mathrm{H}$ : Their relations with each other and two alternative conceptualizations of reliability. psychometrika, 70(1), 123-133.

Zijlmans, E. A., van der Ark, L. A., Tijmstra, J., \& Sijtsma, K. (2018). Methods for estimating item-score reliability. Applied Psychological Measurement, 42(7), 553-570. 


\section{Supplementary materials A}

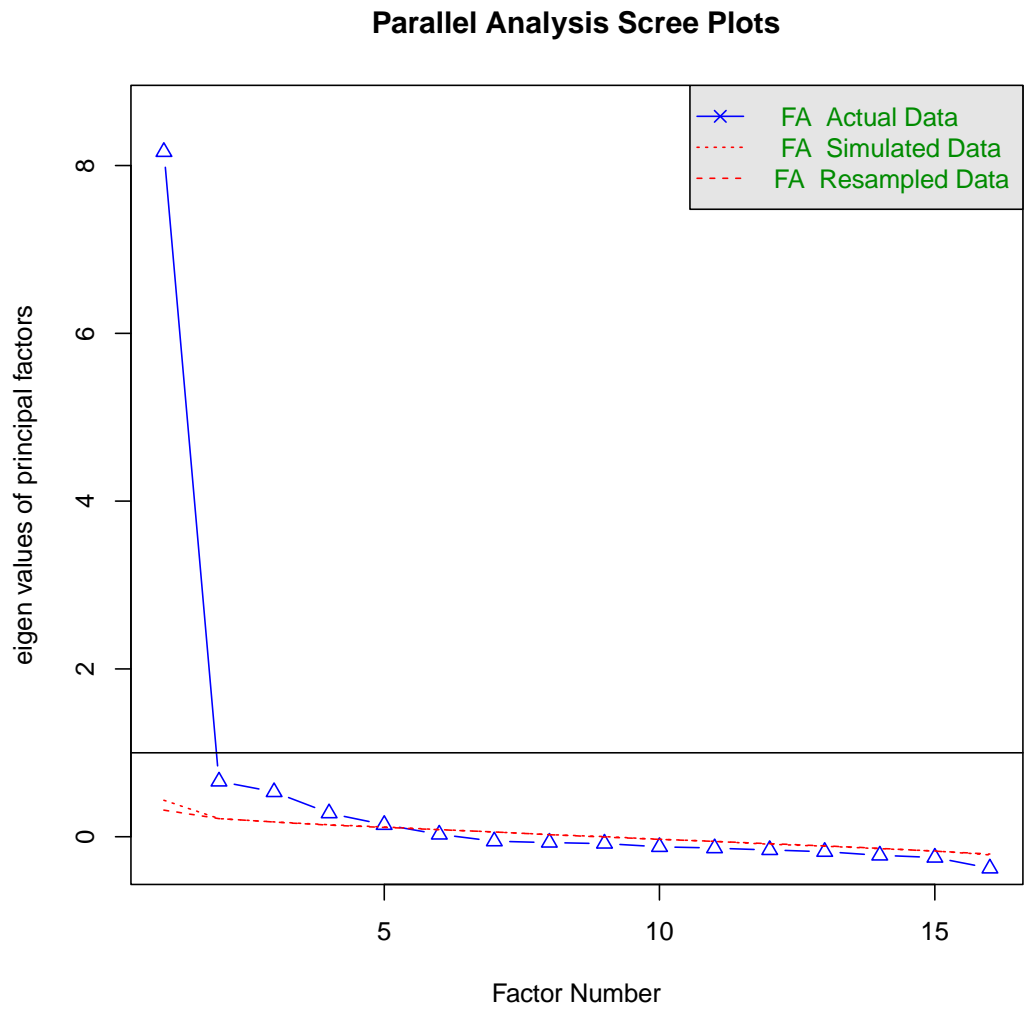




\section{Supplementary materials B}

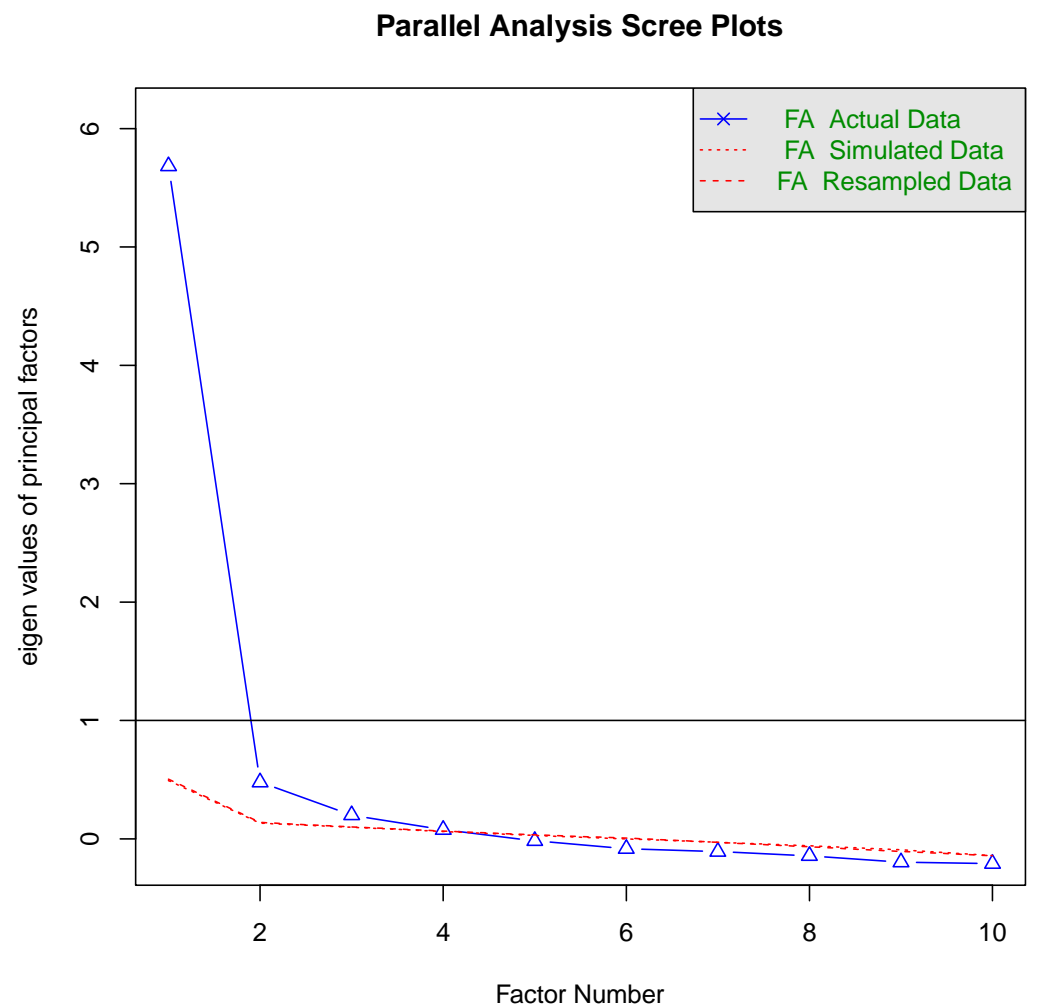

Supplementary materials C. Inter-item correlations of all manifest items and factors of the misogyny scale after EFA (Study 1).

\begin{tabular}{l|lllllllllllll}
\hline Item & 1 & 2 & 3 & 4 & 5 & 6 & 7 & 8 & 9 & 10 & F1 & F2 & F3 \\
\hline 1 & - & & & & & & & & & & & & \\
2 & .63 & - & & & & & & & & & & & \\
3 & .67 & .74 & - & & & & & & & & & & \\
4 & .71 & .70 & .76 & & & & & & & & & & \\
5 & .58 & .46 & .59 & .59 & - & & & & & & & \\
6 & .62 & .52 & .62 & .65 & .76 & - & & & & & & \\
7 & .64 & .58 & .66 & .67 & .69 & .75 & - & & & & & \\
8 & .48 & .37 & .48 & .46 & .50 & .53 & .54 & - & & & & & \\
9 & .36 & .32 & .43 & .41 & .46 & .47 & .46 & .57 & - & & & & \\
10 & .43 & .34 & .43 & .43 & .48 & .50 & .47 & .46 & .53 & - & & & \\
F1 & .85 & .87 & .91 & .91 & .63 & .68 & .72 & .51 & .43 & .46 & - & & \\
F2 & .68 & .58 & .69 & .70 & .89 & .93 & .90 & .58 & .51 & .53 & - & - & \\
F3 & .51 & .42 & .55 & .53 & .59 & .61 & .59 & .84 & .85 & .78 & - & - & - \\
\hline
\end{tabular}


Supplementary materials D. Correlations and covariances between all manifest items and factors and latent correlations between all factors of the finalised misogyny scale after CFA (Study 2).

\begin{tabular}{l|lllllllllllll}
\hline Item & \multicolumn{1}{l}{1} & 2 & 3 & 4 & 5 & 6 & 7 & 8 & 9 & 10 & F1 & F2 & F3 \\
\hline 1 & 2.80 & 1.67 & 1.84 & 1.99 & 1.28 & 1.41 & 1.58 & .98 & .81 & .73 & - & - & - \\
2 & .62 & 2.99 & 1.91 & 2.07 & 1.33 & 1.47 & 1.63 & 1.02 & .84 & .76 & - & - & - \\
3 & .63 & .70 & 2.72 & 2.28 & 1.46 & 1.61 & 1.79 & 1.12 & .93 & .84 & - & - & - \\
4 & .69 & .68 & .76 & 2.92 & 1.58 & 1.75 & 1.93 & 1.21 & 1.00 & .90 & & & \\
5 & 60 & .51 & .61 & .67 & 2.08 & 1.43 & 1.58 & 1.04 & .86 & .74 & - & - & - \\
6 & .59 & .56 & .65 & .70 & .70 & 2.10 & 1.74 & 1.15 & .95 & .81 & - & - & - \\
7 & .62 & .58 & .66 & .73 & .65 & .76 & 2.53 & 1.28 & 1.05 & .89 & - & - & - \\
8 & .52 & .47 & 51 & .53 & .53 & .56 & .57 & 1.96 & .89 & .85 & - & - & - \\
9 & .40 & .33 & .46 & .48 & .49 & .51 & .50 & .57 & 1.47 & .71 & - & - & - \\
10 & .39 & .37 & .42 & .43 & .48 & .44 & .48 & .47 & .55 & 1.39 & - & - & - \\
F1 & .84 & .86 & .90 & .91 & .68 & .71 & .74 & .58 & .47 & .46 & 1.60 & 1.29 & 1.00 \\
F2 & .67 & .62 & .72 & .77 & .87 & .91 & .91 & .62 & .55 & .52 & .89 & 1.31 & 1.02 \\
F3 & .53 & .48 & .56 & .58 & .60 & .61 & .62 & .87 & .85 & .80 & .73 & .82 & 1.17 \\
\hline
\end{tabular}


MEASURING INDIVIDUALS’ MISOGYNISTIC ATTITUDES

Supplementary materials E. Standardised factor loadings and fit indices of models for each group.

\begin{tabular}{|c|c|c|c|c|c|c|c|c|c|c|c|c|c|c|c|c|}
\hline & \multicolumn{6}{|c|}{ Standardised factor loadings } & \multicolumn{10}{|c|}{ Fit indices of models } \\
\hline & 1 & 2 & 3 & 4 & 5 & 6 & 7 & 8 & 9 & 10 & $\chi^{2} / d f$ & $d f$ & $\mathrm{CFI}$ & TLI & RMSEA & SRMR \\
\hline \multicolumn{17}{|l|}{ Gender } \\
\hline $\begin{array}{l}\text { Female } \\
(n=385)\end{array}$ & .72 & .75 & .89 & .92 & .75 & .87 & .85 & .79 & .84 & .68 & 2.29 & 32 & .979 & .971 & .057 & .036 \\
\hline $\begin{array}{l}\text { Male } \\
(n=365)\end{array}$ & .78 & .75 & .87 & .92 & .82 & .86 & .88 & .77 & .70 & .63 & 2.22 & 32 & .977 & .967 & .058 & .034 \\
\hline \multicolumn{17}{|l|}{ Age groups } \\
\hline $\begin{array}{l}\text { Age group } 1 \\
(n=157)\end{array}$ & .76 & .77 & .85 & .89 & .84 & .91 & .79 & .74 & .66 & .60 & 1.45 & 32 & .984 & .978 & .053 & .034 \\
\hline $\begin{array}{l}\text { Age group } 2 \\
(n=279)\end{array}$ & .77 & .77 & .89 & .93 & .76 & .89 & .88 & .77 & .71 & .64 & 1.97 & 32 & .974 & .968 & .059 & .039 \\
\hline $\begin{array}{l}\text { Age group } 3 \\
(n=314)\end{array}$ & .75 & .75 & .89 & .92 & .78 & .84 & .89 & .83 & .82 & .73 & 1.51 & 32 & .990 & .986 & .040 & .031 \\
\hline
\end{tabular}


MEASURING INDIVIDUALS’ MISOGYNISTIC ATTITUDES

Supplementary materials F. Measurement invariance (configural, metric, and scalar).

\begin{tabular}{|c|c|c|c|c|c|c|c|c|c|c|c|c|}
\hline Model & Comparison & $\chi^{2}(d f)$ & CFI & TLI & RMSEA & SRMR & $\Delta \chi^{2}(\Delta d f)$ & $\Delta \mathrm{CFI}$ & $\Delta \mathrm{TLI}$ & $\triangle \mathrm{RMSEA}$ & $\triangle \mathrm{SRMR}$ & MI \\
\hline \multicolumn{13}{|l|}{ Gender } \\
\hline Model 1: CI & & $142.36(64)$ & .978 & .969 & .057 & .032 & & & & & & \\
\hline Model 2: Metric & Model 1 & $167.03(71)$ & .974 & .967 & .060 & .050 & $24.67(17)^{* * *}$ & -.004 & -.002 & -.003 & -.018 & Met \\
\hline Model 3: Scalar & Model 2 & $207.12(78)$ & .971 & .963 & .063 & .053 & $40.09(7)^{* * *}$ & -.003 & -.004 & -.003 & -.003 & Met \\
\hline Model 4: Eqmeans & Model 3 & $229.78(81)$ & & & & & $22.66(3) * * *$ & & & & & \\
\hline \multicolumn{13}{|l|}{ Age groups } \\
\hline Model 1: CI & & $158.20(96)$ & .983 & .977 & .051 & .037 & & & & & & \\
\hline Model 2: Metric & Model 1 & $188.07(110)$ & .979 & .975 & .053 & .053 & $29.87(14)$ & -.004 & -.002 & -.002 & -.016 & Met \\
\hline Model 3: Scalar & Model 2 & $234.91(124)$ & .975 & .972 & .057 & .057 & $46.84(14) * * *$ & -.004 & -.003 & -.004 & -.004 & Met \\
\hline Model 4: Eqmeans & Model 3 & $267.62(130)$ & & & & & $32.71(6)^{* * *}$ & & & & & \\
\hline
\end{tabular}

Notes: Statistically significant $\Delta \chi^{2}$ were marked with '*'. The Satorra-Bentler scaled chi-square difference test is reported. CI $=$ configural invariance; Metric $=$ Metric invariance; Scalar $=$ Scalar invariance $;$ Eqmeans $=$ Equal group means. $\mathrm{MI}=$ measurement invariance. 
Supplementary materials G. Latent Mean Differences.

\begin{tabular}{llll}
\hline Model & Factor & $M_{\text {Diff }}$ & Cohen's $d$ \\
\hline Gender, Male = & & & .38 \\
& F1 & $-.482^{* * *}$ & .27 \\
& F2 & $-.324 * * *$ & .19 \\
Age Groups & F3 & $-.197 * * *$ & \\
Age group 1-2 & F1 & & .14 \\
& F2 & $.187^{* * * *}$ & .02 \\
Age group 1-3 & F3 & -.019 & .05 \\
& F1 & -.048 & .28 \\
& F2 & $.333^{* * * *}$ & .05 \\
Age group 2-3 & F3 & -.055 & .17 \\
& F1 & $-.159 * * *$ & .13 \\
& F2 & $.166^{* * *}$ & .03 \\
& F3 & -.038 & .14 \\
\hline
\end{tabular}

